\title{
Recombinant insulin in type 2 diabetes treatment: where are we now?
}

\author{
Giuseppina T. Russo, Provvidenza Villari, Elisabetta L Romeo, Annalisa Giandalia, \\ Domenico Cucinotta*
}

Department of Clinical and Experimental Medicine, University of Messina, Italy

\section{Email address:}

domenico.cucinotta@unime.it (D. Cucinotta)

\section{To cite this article:}

Giuseppina T. Russo, Provvidenza Villari, Elisabetta L Romeo, Annalisa Giandalia, Domenico Cucinotta. Recombinant Insulin in Type 2 Diabetes Treatment: Where Are We Now?. Science Journal of Clinical Medicine. Vol. 1, No. 1, 2012, pp. 4-9.

doi: $10.11648 /$ j.sjcm.20120101.12

\begin{abstract}
Several insulin formulations are currently available for clinical use, including human regular and protaminated insulins, rapid- and long- acting analogs and premixed combinations, which can be used in different regimens. However, there is no consensus on which are the insulin formulation and the insulin regimen of choice, especially in type 2 diabetes. Overall, insulin analogs are preferred for their better pharmacological properties with a minor hypoglycaemic risk, whereas their superiority in reducing HbAlc levels is still debated. Despite the impressive steps undertaken so far, insulin therapy is still too complex and burdensome, and even with an intensified regimen, only a modest percentage of subjects reaches HbAlc goals. New insulin formulations and devices are currently awaited to better fulfill the still unmet needs of insulin therapy.
\end{abstract}

Keywords: Insulin Analogs, Type 2 Diabetes, Hypoglycaemia, Hba1c

\section{Recombinant Human Insulins}

Since 1922, when substitutive therapy with insulin extracted from animal pancreas was initiated, medical research has made a great effort to reproduce the physiological insulin profile, i.e., a basal insulin secretion to control hepatic glucose output and insulin peaks to overcome postprandial glucose (PPG) excursions. In most countries, two formulations of human insulin, synthesized by recombinant DNA technique, are into the market, namely Regular Human Insulin (RHI) and the intermediate-acting Neutral Protamine Hagedorn (NPH).

$\mathrm{RHI}$ is a molecular hexamer, which must break down into monomers to be absorbed by subcutaneous (s.c.) tissue. Its slow onset and relatively long duration of action and the need to take injections 30-45 minutes prior to meal represent important limitations to its use [1, 2]. Furthermore, RHI peak concentrations may not occur until 2-4 hours after injection, exposing the patient to postprandial hyperglycemia and the risk of subsequent hypoglycaemia [1,2]. NPH insulin can be used to replace or supplement basal insulin, but its profile shows a distinct peak and a limited duration of action, that does not mirror the flat physiological basal insulin secretion $[1,2]$.

\section{Rapid- Acting Insulin Analogs}

Insulin analogs, i.e. modified recombinant human insulins, were developed to overcome the pharmacokinetic (PK) and pharmacodinamic (PD) limitations of RHI and NPH (Table 1) $[1,2]$. Insulin lispro, aspart, and glulisine are the three currently available rapid acting analogs (RAAs) [3]. Lispro, the first to get the market, has been obtained by exchanging proline at position B28 with lysine at position B29 (LysB28, ProB29) in insulin chain [4]; in insulin aspart (AspB28) proline B28 is substituted with aspartic acid [5], and glulisine has two amino acids substitutions, i.e. B3 lysine instead of asparagine and B29 glutamic acid for lysine [6]. Thanks to these structural modifications at crucial sites of the insulin molecule, all RAAs are characterized by reduced tendency for self-association, faster absorption, higher peak serum levels, and shorter duration of action, when compared with RHI.

However, despite their pharmacologycal superiority, comparative clinical data with RHI yielded conflicting results. A meta-analysis by Plank et al. [7], including 42 randomized controlled trials (RCTs) with over 7900 patients with type 1 (T1DM), type 2 (T2DM) or gestational diabetes, demonstrated a small but significant improvement of $\mathrm{HbA} 1 \mathrm{c}$ only in T1DM, but no differences in T2DM patients. Con- 
versely, another meta-analysis [8], analyzing data from 13 RCTs on T2DM, showed that RAAs provided a better control of HbA1c and postprandial glucose (PPG) over RHI, without any significant difference in the overall rate of severe hypoglycaemia, thus confirming various reports on the advantages of RAAs on meal time glucose excursions [9]. Results by Plank et al. were also confirmed by a more recent meta-analysis by Rys et al. on insulin aspart (IAsp) [10], not showing a significant effect on HbA1c and PPG in T2DM subjects.

Table 1. Current available insulin analogs.

\begin{tabular}{|c|c|c|}
\hline Molecule (Trade company) & $\begin{array}{l}\text { Insulin type } \\
\text { and structure }\end{array}$ & Drug kinetics \\
\hline \multicolumn{3}{|l|}{ Rapid-acting } \\
\hline Lispro (Eli Lilly $®$ ) & Lys (B28) Pro (B29) & $\begin{array}{l}\text { Beginning } 10-15 \text { min } \\
\text { Peak } 1-3 \text { hours } \\
\text { Duration } 3-4 \text { hours } \\
\text { Beginning } 10-15 \text { min }\end{array}$ \\
\hline Aspart (Novo Nordisk ${ }^{\circledR}$ ) & Asp (B28) & $\begin{array}{l}\text { Peak 1-3 hours } \\
\text { Duration } 3-4 \text { hours } \\
\text { Beginning } 0-15 \text { min }\end{array}$ \\
\hline Glulisyne (Sanofi Aventis ${ }^{\circledR}$ ) & Lys (B3) Glu (B29) & $\begin{array}{l}\text { Peak } 0.5-1.5 \text { hours } \\
\text { Duration } 3-4 \text { hours }\end{array}$ \\
\hline \multicolumn{3}{|l|}{ Intermediate-acting } \\
\hline Lispro protamin (Eli Lilly $\left.{ }^{\circledR}\right)$ & Lys (B28) Pro (B29) plus protamine & $\begin{array}{l}\text { Beginning } 2 \text { - } 4 \text { hours } \\
\text { Peak } 5 \text { - } 6 \text { hours } \\
\text { Duration } 15-17 \text { hours }\end{array}$ \\
\hline \multicolumn{3}{|l|}{ Long-acting } \\
\hline Detemir (NovoNordisk $®)$ & Lys B29 (N-tetradecanoyl) des (B30) & $\begin{array}{l}\text { Beginning } 2 \text { hours } \\
\text { No peak } \\
\text { Duration about } 20 \text { hours } \\
\text { Beginning } 1-2 \text { hours }\end{array}$ \\
\hline Glargine (SanofiAventis $®$ ) & Gli (A21) Arg (B31) Arg (B32) & $\begin{array}{l}\text { No peak } \\
\text { Duration about } 24 \text { hours }\end{array}$ \\
\hline \multicolumn{3}{|l|}{ Premixed } \\
\hline Different mixtures available & $\begin{array}{l}\text { Premixed rapid-acting } \\
\text { and protamine-bound analogues }\end{array}$ & $\begin{array}{l}\text { Beginning } 15 \text { min } \\
\text { Peak } 0.5-1.2 \text { hours } \\
\text { Duration } 13-16 \text { hours }\end{array}$ \\
\hline
\end{tabular}

The results of these meta-analyses may be relevant when evaluating the economic costs associated with recombinant technologies, although the possible long-term benefits of RAAs, including the potential cardiovascular advantage of specifically targeting PPG excursions [11], should also be taken into account.

Overall, different RAAs have shown a similar efficacy in reducing PPG excursions and the rate of hypoglycaemia and their mitogenic activity is comparable to that of human insulin $[3,12]$.

Some differences exist for the use of different RAAs in pregnancy: insulin aspart has been specifically tested in several RCTs and it has received registration for this indication; insulin lispro has been shown to be safe in several observational studies, whereas no published data on the use of glulisine in pregnant women are available yet [18-20].

\section{Long-Acting Insulin Analogs}

The shorter duration of action of RAAs with respect to RHI has unveiled the need of long-acting peak-less insulin preparations to guarantee basal insulinization and to avoid pre-prandial glucose increase, especially in insulin-deficient individuals [16].

Two long-acting analogs (LAAs) are currently available for clinical use (table 1). Insulin glargine results from the addition of two arginine residues in the $\mathrm{B}$ chain, and the substitution of asparagine with glycine at the A21 residue (A21Gly, B31Arg, B32Arg). These modifications make glargine less soluble at physiological $\mathrm{pH}$ levels, and lead to the deposition of microprecipitates in the s.c. tissue, thus delaying its absorption and prolonging its duration of action $[17,18]$. Detemir is a structurally modified insulin by means of a deletion of treonine on B-chain and acylation of lisine B29 with miristic acid. Detemir is soluble at a neutral $\mathrm{pH}$, tends to self-association and reversibly binds to albumin, which is responsible for its slow absorption and protracted duration of action when compared to NPH. Furthermore, since detemir remains soluble once injected in s.c. tissue, this seems to reduce insulin inter- and intrapatient variability $[17,19]$.

Numerous large, multicenter RCTs have compared NPH insulin with either insulin glargine or detemir. A meta-analysis [20] showed that LAAs are as effective as NPH in terms of glucose control in T2DM patients, although more patients in the glargine or detemir groups achieved glucose targets without nocturnal hypoglycaemia, and with higher treatment satisfaction scores $[21,22]$. Recently, the SOLVE study, the largest multicenter observational trial on insulin therapy in T2DM, demonstrated that insulin detemir was effective and safe also in the "real life" setting of patients that are not usually included in the registration trials, i.e., those who start insulin therapy late, when hypoglycemic risk 
is higher because of an older age and concomitant long-term complications [23].

PK and PD properties of NPH and the two available LAAs were recently compared in $18 \mathrm{~T} 2 \mathrm{DM}$ subjects, who underwent repeatedly euglycaemic clamps. In this study, insulin glargine provided a greater metabolic activity and superior glucose control for up $32 \mathrm{~h}$, with a mean GIR0-32 h, a surrogate measure of insulin metabolic activity, that was $31 \%$ greater than NPH and $42 \%$ higher than insulin detemir [24]. However, several head-to-head studies that have compared the efficacy and safety of insulin glargine and detemir showed no significant differences with respect to glycemic control and both nocturnal and severe hypoglycemia [25]. Notably, insulin detemir was associated with more frequent twice-a-day need of use, an higher insulin dose requirement and lesser weight gain, when compared to glargine [26-29]. The reasons for the lower weight gain with insulin detemir are not completely understood, although they may be related to a reduced energy intake involving hormones regulating satiety [30].

To date, there is no specific information on the use of LAAs in pregnancy, although both LAAs are usually prescribed off-label, and large surveys showed that they are safe and well tolerated compared with human insulin [13-15].

Some concern has been recently raised regarding a major safety issue with the use of insulin glargine, i.e. that of a potentially increased cancer risk. This concern comes from some observational, mainly retrospective studies and it is especially related with the incidence of breast cancer; however, subsequent data did not report any disparity in cancer incidence between participants treated with insulin glargine and those treated with other types of insulin $[31,32]$ Furthermore, the American Diabetes Association and the American Cancer Society recently published a joint consensus report that did not lead to firm conclusions on insulin therapy and cancer risk [33].

\section{Premixed Insulin Analogs}

Another, more convenient and largely used approach to insulin therapy is that based on "premixed" insulins, consisting of a fixed combination of NPH and RHI or RAA, in different ratios. These biphasic insulins are usually administered twice daily, before morning and evening meals.

In T2DM, against basal insulins once daily, biphasic insulin analogs twice daily seem to perform better in achieving the glucose targets and, even when compared with the more complex basal-bolus regimens, these premixed insulins are at least non-inferior. A recent systematic review, investigating the role of different insulin analogs in achieving optimal HbA1c targets in T2DM, showed that biphasic insulins ranked second, after the basal-bolus scheme [34]. Usually, side effects are no more frequent than with other insulins; more hypoglycemic episodes of low severity have been sometimes reported, but only in comparison with basal insulin $[35,36]$. Although premixed insulin analogs may represent a more convenient insulin regimen, especially for patients who need a simplified approach, the inability to separately titrate the shorter- and the longer-acting component of these formulations makes it a poorly flexible approach and greatly limits its use.

\section{Novel Insulins}

Despite the progress in insulin therapy made so far, the search of novel insulins with a better PD/PK profile, allowing a more convenient timing or way of administration is still ongoing, and several new products are close to reach the market. Among these new formulations, there are faster insulins, such as VIAject (Biodel Inc. Danbury, CT), with a more rapid onset of action, potentially even faster than the currently available RAAs, and others, which are aimed to ameliorate current LAAs' properties, such as BIOD-Adjustable Basal (Biodel Inc. Danbury, CT), and BIOD-Smart Basal, including glargine in their molecules [37-39].

The first to be available for use will be insulin degludec (Novo Nordisk), a phase 3 LAA which retains the human insulin amino acid sequence except for the deletion of ThrB30 and the addition of a 16-carbon fatty diacid attached to LysB29 via a glutamic acid spacer. It has an ultra-long (up to $96 \mathrm{hrs}$ ) life-time, derived from the soluble multi-hexamers formation, resulting in a continuous slow and stable release of insulin monomers from s.c. tissue [37,39,40]. Compared to basal insulin glargine, degludec has shown similar glycemic control and rate of hypoglicaemia, depending on the regimen used [48-51]. The BEGIN, Basal-Bolus Type 2, studies showed that insulin degludec was non-inferior to glargine in terms of glucose control, when both were administrated once a day in a basal bolus regimen, and it was associated with a lower risk of hypoglycemia [41].

\section{Expert Opinion}

Many T2DM subjects will eventually need insulin therapy because of the progressive loss of beta-cell function over time. The aim of insulin treatment is to recreate insulin levels and mode of action as close as possible to the physiological profile, in order to achieve a tight glucose control, to reduce the risk of hypoglycaemia and to improve quality of patients' life.

While in T1DM it is an obligate choice, prescribing insulin therapy in T2DM patients is still problematic. Despite the potential benefits of early insulinization to preserve beta-cell function, insulin therapy is often delayed because of numerous barriers in both patients and care-givers, including the fear of hypoglycaemia and weight gain, difficulties in insulin titration, and the necessity of multiple daily glucose controls. Insulin analogs, either alone or in premixed formulations, have simplified several of these points.

However, there is no consensus on which regimen should be preferred to start insulin therapy in these patients. Actually, once daily basal insulin, added to the previously used oral agents, is the most popular regimen, and it is able to 
ameliorate glucose control in the majority of T2DM patients, as demonstrated by the "treat to target" trials [21,22,28,29].

Twice a day premixed insulins [42] or a basal-plus scheme with a rapid-acting insulin at the mean meal [43] represent valid alternatives. Finally, a basal-bolus regimen may also be used in T2DM, when the more simplified ones are no longer effective [44].

In this context, Pontiroli et al [45] recently analyzed the effect of different insulin regimens and insulin analogs in T2DM during the first year of insulin treatment. This meta-analysis found that both glucose control and the risk of hypoglycaemia were primarily associated with the intensity of treatment, with final $\mathrm{HbAlc}$ that was higher with basal than with twice-a-day or prandial regimen, and with opposite figures for hypoglycaemia. Within basal regimens, detemir and glargine were similar to NPH in HbAlc lowering, with less hypoglycaemia, whereas within prandial regimens, RAAs were more effective than $\mathrm{RHI}$ on $\mathrm{HbAlc}$, and induced less hypoglycaemia.

In a large meta-analysis involving $>32,000$ patients, Giugliano et al found that insulin analogs resulted in different success rate in achieving HbA1c targets in T2DM [34]. However, even with the best approach to insulin therapy, i.e., basal-bolus regimen, there were a considerable percentage of subjects not reaching HbAlc goals [23], although the appropriateness of an intensive glucose control in all T2DM subjects is today a highly debated issue, especially in the light of reducing cardiovascular risk $[46,47]$.

Furthermore, several trials investigated the "durability" of glucose control with different starter insulin regimens. The DURABLE trial demonstrated a modestly longer maintenance of $\mathrm{HbAlc}$ levels $\leq 7 \%$ in T2DM patients treated with twice daily premixed lispro formulations than with once daily glargine plus oral agents $(43 \%$ vs. $35 \%)$, with an overall longer duration of glucose control in patients with lower HbA1c at baseline [48]. This study further demonstrated the benefits of early initiation of insulin therapy and, as reported in the Treating to Target in Type 2 Diabetes Trial (4-T), the relatively short duration of control in T2DM, in spite of any insulin regimen [49].

In the last decades, insulin therapy has made several steps forward and recombinant DNA technology has made available different formulations for clinical use, starting from human insulins (RHI and NPH) and coming to the current analogs, and to novel insulins that are ready to be introduced into the market.

Insulin analogs have ameliorated several critical points of insulin therapy, i.e., timing of insulin administration, flat basal profile, and hypoglycemic risk. Overall, both RAAs and LAAs seem to better perform in basal-bolus schemes, representing the insulins of choice in T1DM. In T2DM, different schemes, either with recombinant insulin or insulin analogs seem to be efficacious in targeting $\mathrm{HbAlc}$, although analogs should be preferred when considering hypoglycemic risk and the opportunity to tailor treatment on patients' lifestyle.

Nevertheless, many problems persist: although improved, the possibility to achieve an optimal plasma glucose control while avoiding hypoglycaemia is still far from being obtained in many patients; furthermore, the selection of which insulin regimen will better fit patients' needs is still challenging, not to mention the uncomfortable route of administration.

For these reasons, new insulin formulations and devices are under intensive research and it is likely that in a relatively short period of time insulin therapy will be enriched by these new opportunities, that hopefully will represent a progress on the long way to match a system that is perfectly regulated in nature, i.e. the physiological insulin secretion and action.

\section{References}

[1] DeWitt DE, Hirsch IB. Outpatient insulin therapy in type 1 and type 2 diabetes mellitus: scientific review. JAMA. 2003;289:2254-64.

[2] Gerich JE. Novel insulins: expanding options in diabetes management. Am J Med 2002;113:308-316.

[3] Bode BW. Comparison of pharmacokinetic properties, physicochemical stability, and pump compatibility of 3 rapid-acting insulin analogues - aspart, lispro, and glulisine. Endocr Pract. 2011;17:271-80.

[4] Howey DC, Bowsher RR, Brunelle RL, et al. [Lys(B28),Pro(B29)]- human insulin. A rapidly absorbed analogue of human insulin. Diabetes 1994;43:396-402.

[5] Vajo Z, Fawcett J, Duckworth WC. Recombinant DNA technology in the treatment of diabetes: insulin analogs. Endocr Rev. 2001;22:706-17.

[6] Ulrich H, Snyde B, Satish KG. Combining insulins for optimal blood glucose control in type 1 and 2 diabetes: Focus on insulin glulisine.Vascul Health And Risk Management 2007;3:245-254

[7] Plank J, Siebenhofer A, Berghold A, et al. Systematic review and meta-analysis of short-acting insulin analogues in patients with diabetes mellitus. Arch Intern Med 2005;165:1337-44.

[8] Mannucci E, Monami M, Marchionni N. Short-acting insulin analogues vs. regular human insulin in type 2 diabetes: a meta-analysis. Diabetes Obes Metab 2009;11:53-9.

[9] Perriello G, Pampanelli S, Porcellati F, et al. Insulin aspart improves meal time glycaemic control in patients with Type 2diabetes: a randomized, stratified, double-blind and cross-over trial. Diabet Med 2005;22:606-11.

[10] Rys P, Pankiewicz O, Łach K, et al.Efficacy and safety comparison of rapid-acting insulin aspart and regular human insulin in the treatment of type 1 and type 2 diabetes mellitus: a systematic review. Diabetes Metab 2011;37:190-200.

[11] Blaak EE, Antoine JM, Benton D, et al. Impact of postprandial glycaemia on health and prevention of disease. Obes Rev 2012. doi: 10.1111/j.1467-789X.2012.01011.x.

[12] Home PD. The pharmacokinetics and pharmacodynamics of rapid-acting insulin analogues and their clinical conse- 
quences. Diabetes Obes Metab 2012;14:780-8.

[13] Torlone E, Di Cianni G, Mannino D, et al. Insulin analogs and pregnancy: an update. Acta Diabetol 2009;46:163-72.

[14] Durnwald CP, Landon MB. Insulin analogues in the management of the pregnancy complicated by diabetes mellitus. Curr Diab Rep 2011;11:28-34.

[15] de Valk HW, Visser GH. Insulin during pregnancy, labour and delivery. Best Pract Res Clin Obstet Gynaecol 2011;25:65-76.

[16] G.B. Bolli, R. D. Di Marchi, G. D. Park, et al. Insulin analogues and their potential in the management of diabetes mellitus Diabetologia 1999;42:1151-1167.

[17] Maka S, Hedrington MD, Lindsay Pulliam BS et al. Basal insulin treatment in type 2 diabetes. Diabetes technology \& therapeutics 2011;13:Suppl 1 (S 33-42).

[18] Sanofi-Aventis. Lantus. Prescribing Information. Revised 2007 http://products.sanofi-aventis.us/lantus/lantus.pdf.

[19] Levemir ${ }^{\circledR}$ (insulin detemir [rDNA origin] injection) [prescribing information]. Princeton, NJ: Novo Nordisk Inc 2010 .

[20] Monami M, Marchionni N, Mannucci E. Long-acting insulin analogues versus NPH human insulin in type 2 diabetes: a meta-analysis. Diabetes Res Clin Pract 2008;81:184-9.

[21] Riddle MC, Rosenstock J, Gerich J. Insulin Glargine 4002 Study Investigators. The treat-to-target trial: randomized addition of glargine or human NPH insulin to oral therapy of type 2 diabetic patients. Diabetes Care 2003;26:3080-6.

[22] Hermansen K, Davies M, Derezinski T, et al. A 26-week, randomized, parallel, treat-to-target trial comparing insulin detemir with NPH insulin as add-on therapy to oral glucose-lowering drugs in insulin-naive people with type 2 diabetes. Diabetes Care 2006;29:1269-74.

[23] Khunti K, Damci T, Meneghini L, et al. SOLVE Study Group. Study of Once Daily Levemir (SOLVETM): insights into the timing of insulin initiation in people with poorly controlled type 2 diabetes in routine clinical practice. Diabetes Obes Metab 2012;14:654-61.

[24] Lucidi P, Porcellati F, Rossetti P, et al. Pharmacokinetics and pharmacodynamics of therapeutic doses of basal insulins $\mathrm{NPH}$, glargine, and detemir after 1 week of daily administration at bedtime in type 2 diabetic subjects: a randomized cross-over study. Diabetes Care 2011;34:1312-4.

[25] Swinnen SG, Simon AC, Holleman F, et al. Insulin detemir versus insulin glargine for type 2 diabetes mellitus. Cochrane Database of Systematic Reviews 2011;7:CD006383. DOI: 10.1002/14651858. CD006383.pub.2

[26] 26. Raskin P, Gylvin T, Weng W, et al. Comparison of insulin detemir and insulin glargine using a basal-bolus regimen in a randomized, controlled clinical study in patients with type 2 diabetes. Diabetes Metab Res Rev 2009;25:542-548.

[27] Hollander P, Cooper J, Bregnhøj J, et al. A 52-week, multinational, open-label, parallel-group, noninferiority, treat-to-target trial comparing insulin detemir with insulin glargine in a basal-bolus regimen with mealtime insulin aspart in patients with type 2 diabetes. Clin Ther 2008;30:1976-1987.
[28] Rosenstock J, Davies M, Home PD, et al. A randomised, 52-week, treat-to-target trial comparing insulin detemir with insulin glargine when administered as add-on to glucose-lowering drugs in insulin naive people with type 2 diabetes. Diabetologia 2008;51: 408-416.

[29] Swinnen SG, Dain MP, Aronson R, et al. A 24-week, randomized, treat-to-target trial comparing initiation of insulin glargine once-daily with insulin detemir twice-daily in patients with type 2 diabetes inadequately controlled on oral glucose-lowering drugs. Diabetes Care 2010;33:1176-1178.

[30] Zachariah S, Sheldon B, Shojaee-Moradie F, et al. Insulin detemir reduces weight gain as a result of reduced food intake in patients with type 1 diabetes. Diabetes care 2011;34:1487-1491.

[31] Call R, Grimsley M, Cadwallader L, et al. Insulin--carcinogen or mitogen? Preclinical and clinical evidence from prostate, breast, pancreatic, and colorectal cancer research. Postgrad Med 2010;122:158-65.

[32] Home PD, Lagarenne P. Combined randomised controlled trial experience of malignancies in studies using insulin glargine. Diabetologia 2009;52:2499-506.

[33] Giovannucci E, Harlan DM, Archer MC, et al. Diabetes and cancer: a consensus report. CA Cancer J Clin 2010;60:207-21.

[34] Giugliano D, Maiorino MI, Bellastella G, et al. Multiple HbAlc targets and insulin analogues in type 2 diabetes: a systematic review. J Diabetes Complications 2011;25:275-81.

[35] Cucinotta D, Russo G. Biphasic insulin aspart in the treatment of type 2 diabetes mellitus. Expert Opin Pharmacother 2009;10:2905-11.

[36] Davidson J, Vexiau P, Cucinotta D, et al. R. Biphasic insulin aspart 30: literature review of adverse events associated with treatment. Clin Ther. 2005;27 Suppl B:S75-88.

[37] Danne T, Bolinder J. New insulins and insulin therapy. Int J Clin Pract Suppl 2011;170:26-30.

[38] Steiner S, Hompesch M, Pohl R, et al. A novel insulin formulation with a more rapid onset of action. Diabetologia. 2008;51:1602-6.

[39] Simon AC, DeVries JH. The future of basal insulin supplementation. Diabetes Technol Ther 2011;13 Suppl 1:S103-8.

[40] Kalra S, Unnikrishnan AG, Baruah M, et al. Degludec insulin: A novel basal insulin. J Endocrinol Metab 2011;15:S12-6.

[41] Garber AJ, King AB, Del Prato S, et al. NN1250-3582 (BEGIN BB T2D) Trial Investigators. Insulin degludec, an ultra-long-acting basal insulin, versus insulin glargine in basal-bolus treatment with mealtime insulin aspart in type 2 diabetes (BEGIN Basal-Bolus Type 2): a phase 3, randomised, open-label, treat-to-target non-inferiority trial. Lancet 2012;379: 1498-507.

[42] Lasserson DS, Glasziou P, Perera R, et al. Optimal insulin regimens in type 2 diabetes mellitus: systematic review and meta-analyses. Diabetologia 2009;52:1990-2000.

[43] Nicolucci A, Del Prato S, Vespasiani G; ELEONOR Study Group. Optimizing insulin glargine plus one injection of insulin glulisine in type 2 diabetes in the ELEONOR study: 
similar effects of telecare and conventional self-monitoring of blood glucose on patient functional health status and treatment satisfaction. Diabetes Care 2011;34:2524-6.

[44] Management of Hyperglycemia in Type 2 Diabetes: A Patient-Centered Approach. Position Statement of the American Diabetes Association (ADA) and the European Association for the Study of Diabetes (EASD). Diabetes Care, published online April 19, 2012.

[45] Pontiroli AE, Miele L, Morabito A. Metabolic control and risk of hypoglycaemia during the first year of intensive insulin treatment in type 2 diabetes: systematic review and meta-analysis. Diabetes Obes Metab 2012;14:433-46.

[46] Currie CJ, Peters JR, Tynan A, Evans M, et al. Survival as a function of $\mathrm{HbA}(1 \mathrm{c})$ in people with type 2 diabetes: a re- trospective cohort study. Lancet 2010;375:481-9.

[47] Yudkin JS, Richter B, Gale EA. Intensified glucose lowering in type 2 diabetes: time for a reappraisal. Diabetologia 2010;53:2079-85.

[48] Buse JB, Wolffenbuttel BH, Herman WH, et al. The DURAbility of Basal versus Lispro mix 75/25 insulin Efficacy (DURABLE) trial:comparing the durability of lispro mix 75/25 and glargine. Diabetes Care 2011;34:249-55.

[49] Holman RR, Farmer AJ, Davies MJ, et al. 4-T Study Group. Three-year efficacy of complex insulin regimens in type 2 diabetes. N Engl J Med 2009;361:1736-47. 